\title{
Courseware And Small Group Development: A Comparative Analysis
}

\author{
Barbara Mihm, (Email: bmihm@uwsp.edu), University of Wisconsin, Stevens Point
} Karlene Ferrante, University of Wisconsin, Stevens Point

\begin{abstract}
The scholarship of teaching and learning is the basis for this research, which investigated the use of the information technology tool-courseware or software that facilitates collaboration in classroom settings. The study focuses on the use of computer-mediated communication as a tool for group decision-making. The study compared a distance education class in the Collaborative Degree Program at regional mid-size state university to a face-to-face course taught at the same university. The purpose of this work is to better understand group interaction in computer-mediated situations. The results of this study contribute to a growing body of research on the ways evolving technologies impact group collaboration.
\end{abstract}

\section{INTRODUCTION}

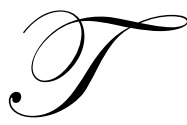

he discussion within the academy continues to focus on systematic inquiry into teaching and learning. Many faculty members who teach in the business and communication disciplines recognize the value for students in translating knowledge about a subject into a better understanding of how to make a decision, complete a task, or solve a problem. It is not sufficient for students to simply know information about a topic; they also need to know how to use that information in realistic ways. Educators also recognize the important opportunities we have for practical application and skill development in class. For example, in management and organizational communication, students learn about the use of teams in organizations. Students study team development and team effectiveness and can apply these concepts to their own experiences within their groups. Business students also study the decision-making process from a functional perspective. As pointed out by Bilimoria \& Fukami (2002) there exists a "fundamental synergy between the content of the business discipline and the substance of teaching and learning" (p.129). Because business classes provide students with both information on how to make better decisions and on practical application of skill development in group decision-making, the discipline offers opportunities for study in the area of group communication in a classroom setting.

In business, organizations are increasingly relying on groups to solve workplace problems. Research shows (Cohen and Bailey, 1997) in organizations with over 100 employees, 82 percent of these companies used teams. Of the Fortune 1000 companies, 68 percent reported using self-managing work teams. This number is up from 28 percent reported in 1987. 91 percent of the companies surveyed reported using employee participation in groups in 1997, as compared to 70 percent 1987. More recently, Lawler (1999) reports that 78 percent of U.S. corporations are using self-managing work teams. Some researchers go so far as to state that teams in one form or another exist in virtually all organizations (Bateman \& Snell, 2004). This shift is a clear indication that teams are not a passing fad, but are a critical part of helping organizations get work done more effectively with the use of employee involvement. Furthermore, the ability to communicate and work with others is of high importance to employers when hiring. Research investigating preparation for career success found collaboration skills and problem solving skills highly important (Uchida, 1996). Teamwork and the ability to work with others are imperative in today's workplace.

Because of these trends, it is increasingly important for college instructors to gain a better understanding of small groups in their classrooms, especially as communication technology reshapes the ways in which groups work together to accomplish tasks and meet goals. Many faculty members attempt to use student groups pedagogically in their classrooms; however often the result is less than optimal because students are not provided with enough structure, 
and faculty members do not know how to guide students through the group development process. Oftentimes, group discussions in class are difficult to monitor and are not productive; groups fail to become cohesive, and tasks are not distributed equitably among group members. The use of new collaboration tools such as courseware may possibly improve the group learning experience by aiding groups in productivity, while holding group members more accountable. These types of enhanced group experiences should better prepare students for the business world.

Courseware, which is new in business settings as groupware, is a form of software that facilitates communication. Groupware (Haag, Cummings and McCubbrey, 2004) is defined as a type of software used to support and facilitate team collaboration. There is an array of groupware products available both in business and in education. The main difference between groupware and courseware is that courseware has more options available for delivering material and grading, in addition to the features which facilitate group communication. For this study, the Desire to Learn software, which has been mandated by UW-System, was used. 'D2L' as it is called, was introduced to the campus in 2003, and is being used by an increasing number of faculty for courses which are being taught completely online and also for so called 'hybrid courses' which combine features of the traditional course with online discussion via courseware. Because this course did have some face-to-face meetings it would be considered a hybrid.

\section{THEORETICAL FRAMEWORK}

The research rests on three important bodies of theoretical work: cooperative learning, communication in groups, and communication and technology. The purpose of having students work in groups is to improve learning, and many have investigated the use of cooperative and collaborative learning as methods to actively involve students in the classroom. Communication scholars have examined the process of group problem solving, with an emphasis on improved decision-making. Communication scholars and educators are continuing to examine the impact of technology and courseware in classroom settings.

\section{Cooperative and Collaborative Learning}

Cooperative learning improves results in the classroom by enhancing interpersonal relationships, increasing self-esteem, and improving motivation (Johnson, Johnson \& Smith, 1991; Felder \& Brent, 1996). However, cooperative learning involves more than simply grouping students together. It must involve structured learning activities that promote mutual learning. According to Smith and Waller (1997) cooperative learning must include "positive interdependence, teamwork skills, accountability with personal responsibility, and group processing" (p.193). These key concepts should be fundamental in structuring cooperative learning groups.

Muir and Blake (2000) point out that while collaboration can be formal or informal, the common elements of all collaboration in the classroom are common goals, shared expectations for group contributions and results, and expression of key values which include "community, unity, and respect" (p.1). If these values are not primary for students and instructors collaboration will be difficult, negatively impacting problem solving and goal attainment.

While some scholars use the terms interchangeably, others make the distinction between collaboration and cooperation. However, collaborative learning has a definite emphasis on active learning and knowledge being gained both collectively and socially. The instructor has a clear role, but no longer is seen as the only source of information. Collaborative learning does involve some structure. Tasks are clearly defined and assigned to groups. Then groups are required to work out their strategies collectively. The instructor's role becomes one of facilitator (McGlynn 2001; Nygrarg, 1991; Wiener,1986).

Structured assignments serve a number of purposes. According to Millis (2001) structured assignments provide students the chance to apply the material they have been exposed to, with a goal of moving to a higher level of learning. In this study, students were assigned structured assignments each week. Initial assignments were worth small amounts of points and were designed to engage students with the material and to familiarize them with the group format. Additionally, assigning the students weekly low-stake exercises requiring their interaction and helping them develop interpersonal and team skills builds self-efficacy. Bandura (1991) is perhaps one of those most recognized for work on self-efficacy, which is the confidence to succeed at a task based on past experiences. Effort 
put forth and action taken to complete tasks is related to one's confidence level and their belief in their ability to perform. Studies validate the importance of successful past experiences in the group. In effect, success breeds success for groups. Wolf (1997) applies Bandura's work on enactive mastery, the most significant part of developing selfefficacy, to a study of group problem solving in hospitals. She found both educational level and past experience with problem solving in groups to be highly predictive of building self-efficacy for members of the groups.

In this course, enactive mastery builds self-efficacy by giving group members the chance to succeed in small areas first. Group discussions and a formal group research project are examples of structured group assignments. Discussion formats were set up to give students points simply for participating. The discussions did not require consensus, but the research project did involve many decisions which required agreement including what to research, agreement on how to handle the work, deciding who would do what, and agreeing on what conclusions to draw.

There are clear benefits to a collaborative approach. Students tend to be more engaged and have an increased understanding of the material. Students are more likely to apply the concepts, and there is some evidence students tend to have higher retention of the material (McGlynn, 2001). Because students need to reach an agreement on how to solve the problem, or how to work through the task, communication is an essential part of the collaborative process.

\section{Communication in Group Problem Solving}

Communication researchers theorize that group decision-making is not a linear process, but rather a highly dynamic and circular process. Fisher's (1970) theory of decision emergence details four stages that task groups move through. He states that groups operate in stages of "orientation, conflict, emergence, and reinforcement" (p.54.). The group's interactions vary as the decision begins to take shape. The work done on the stages of team development which are referred to as forming, norming, storming, and performing (Bateman and Snell, 2004) also indicates a dynamic form of communication dependent on the stage the group is in.

Some researchers take issue with the idea of stages in describing group development. Gersick (1988) studied a variety of task teams and found that the groups operate in phases rather than stages. She notes that teams do not move into predictive stages of development but rather they tend to move between inertia and bursts of accomplishment, heavily impacted by time, deadlines, and context of the situation. Further, she found the initial meeting is pivotal to how the group will use its time in the first half of the team's life, implying the importance of group direction and leadership from management.

Significant work on group problem solving and group decision-making began in the 1970's and continues to evolve. Gouran, Hirokawa, Juliam \& Leatham (1993) trace the roots of the functional perspective and summarize the work done in this area, beginning with Bales' (1951) argument that small groups are social systems, to stating the underlying assumptions on which the functional perspective rests. According to Gouran, Hirokawa, Juliam, and Leatham there are seven assumptions that need to be in place for the group to reach effective solutions to problems. These assumptions are: 1)group members must be motivated to make an suitable decision, 2) the choice in not clear, 3) the collective resources of the group outweigh the expertise of individual group members, 4) the requirements of the task are specific, 5) the group has or can obtain relevant information, 6) the group members have the mental abilities to perform the task, 7) communication is the means by which the task can be accomplished (p.579). Clearly, when educators decide to use small groups for problem solving in their classes these assumptions need to be met if effective decisions are to be reached by the group. It is important to note that the project the students worked on was designed to meet the seven assumptions detailed above by Gouran et all for effective problem solving in groups.

Further, Hirokawa (1982) emphasizes that past research from decision-making theorists and small group theorists points to four fundamental functions that help in understanding the behavior of groups. These functions are: "the group must establish a set of operating procedures, the group must understand and analyze the problem, the group must generate feasible alternative solutions to the problem, and the group must evaluate each alternate suggestion before deciding on a final decision or solution" (p.137). 
These functions parallel the typical model for decision-making found in many management texts for business students, which are often listed as diagnosing and identifying the problem, gathering alternative solutions, evaluating the possible solutions, implementing and monitoring the solution (Bartol and Martin, 1998; Batemen and Snell, 2004). In the course Hirokawa's first function "establishing operating procedures" which is important for groups in making decisions, is facilitated by the group contract students developed early in the term. Before moving to making decisions groups need to hammer out the details on how to work together through discussion.

Better discussions can result in improved decision-making. Gouran, Hirokawa, Juliam, and Leatham (1993) stress the importance of high quality discussion on decision- making. Discussions allow for the sharing and grouping of information so all members have resources to understand the problem; discussion allows for group members to correct mistakes in judgement; and perhaps most important when consensus is needed, discussion allows for persuasion among group members. When these conditions are in place, groups should be able to reach higher quality results than in situations where discussions are limited and there is not sufficient interaction between group members to meet the conditions. In this study, structured discussion questions for small groups either in class or online should help ensure these conditions are met.

However, it is essential to recognize that the process of decision-making is not neat and tidy, and that groups move back and forth between ideas and proposals. Fisher's (1970) research with a variety of business organizations is important because it gives insights into the messy form that decision-making in groups may take. Referring to this as "decision modification," he observed that ... "groups did not make decisions gradually by clear and direct amendments but in sudden jumps to different formulations of the same root proposal" (p. 55-56). He details examples of group problem solving that involve clarifying proposals in more concrete language, and putting ideas aside until others in the group had insights into what the consensus is. Group communication that leads to high quality discussion can improve group decisions. In the course that was studied the complexity of decision-making was high. Students needed to select a company for research and then establish what work needed to be done and who was responsible for doing it. They needed to agree on what conclusions to draw. Because there were multiple ways of looking at the problem, hashing out ideas was very important. Stakes were fairly high since a significant portion of their grade rested on the project.

\section{Communication Theory and Technology}

Organizations in business and academic settings continue to use groups to solve problems. And technology continues to impact how groups communicate. Because technology and communication have increasing importance both in today's organizations and in society at large, the topic of technology is of interest to a number of disciplines. Computer-mediated communication is often viewed as a tool to enhance the communication of groups. However, while there is a significant body of research from a variety of theoretical perspectives in computer-assisted or computer-mediated group work, the results are mixed. According to Hollingshead and McGrath (1995), who conducted a critical meta-literature review on the topic, the results are mixed because of confounding of variables, differences in communications systems, and different research methodologies. Additionally, many studies have been conducted in contrived static settings. All of these factors make it difficult to generalize.

While there are a variety of theoretical perspectives, there is some synergy and overlap, particularly within the sociology and communication disciplines. There appear to be three main directions from the research of those working with communication theory and technology. Some scholars use a social constructivist approach viewing the social situation as the determinant for the mode of communication technology, and examine the attitudes impacting the communication (Contractor and Eisenburg, 1990; Fulk 1993, Schmitz and Fulk, 1991; Orlikowski, 1992). Other scholars have directed their focus on the different types of media conditions in communication, and the user's perception of each medium. These studies have attempted to establish the relationship between media and the outcome of the task. For example see Daft and Lengel, 1984, 1986; Dennis and Kinney, 1998; Rice, 1992; Trevino, Daft and Lengel, 1990. More recently, researchers (Burke and Chidambaram, 1999; Carlson and Zmud, 1999; Trevino et all, 2000; Yoo and Alavi 2001; Fulk and Collins-Jarvis, 2001) have attempted to blend media choice, task outcomes, and social influences perspectives in hopes of gaining a better picture of technological communication dynamics and 
media choice. Additionally, in the third group some researchers have applied input-output theory to better understand communication in task-oriented situations. This study falls into the third group.

Those researchers taking a social constructivist approach have directed their inquiry to a general view of the impact of social factors on the choice of media and propose that social factors such as group norms, group cohesiveness, and the culture of the organization are instrumental ways in which media are used in organizations (Fulk,1993; Lee,1994; Ngwenyama and Lee,1997; Orlikowski,1992). Schmitz and Fulk (1991) developed a model that helps explain social influences on the use of e-mail. The model accounts for past experience with e-mail, typing skills, and experiences with computer-based technology. They concluded along with the empirical work of others (Keer and Hiltz, 1982; Johansen, 1988) that expertise and familiarity impact the perceptions of the media being used.

Further research by Fulk (1993) found an important link between social influences and attitudes toward technology and attraction to work groups. An extensive survey was conducted in a business organization whose group members used e-mail. Fulk included the model mentioned above when analyzing her findings. She found task variable and social influences impacted attitudes toward technology. Fulk's study is important because it took into account the level of experience of the users, finding their experiences impacted the acceptance of technology. More importantly according to Fulk, "the results showed that work-group social influence explained unique variance in individual attitudes and behaviors, even after ego network-based social influence, media expertise, perceived task features, and demographic characteristics were controlled" (p.941). She concludes that those who have little attraction to a work group will have different attitudes and perceptions of media richness than those with high attraction to their work groups, seeming to verify that media choice and attraction to the group are interrelated.

The second major approach, which is media richness theory (Daft and Lengel 1984, 1986), an outgrowth of social presence theory, proposes that face-to-face communication is the richest form of communication. Daft and Lengel argue that face-to-face communication is best for situations which require high levels of interpersonal interactions because the tasks are not clear. Their theory proposes that media richness is an important part of media capacity influencing communication in groups. According to media richness theory, tasks that are more complex and ambiguous often are impeded by technological communication, and face-to face communication is better in these situations. They argue that lean media such as the written text, found in e-mail, is better suited for clearly defined and less ambiguous tasks.

Attempting to build on media richness theory, group decision-making theory, and social influence factors, Yoo and Alavi (2001) conducted an experiment comparing audio conferencing to desk top video conferencing to measure the "relative influence of media condition and group cohesion on social presence, task participation, and group consensus"(p.371). Their findings suggest that attention to group development and cohesion can reduce task complexity when electronic communication is used. This study is important in that it uses a comparison of two forms of technology in task and problem solving situations and accounts for group history; however it does not include groupware technology which is more common than desk-top video conferencing.

While the work of Yoo and Alavi is significant because it provides both managers and instructors a better understanding of the relationship and task areas of communication, it was conducted like many communication studies, in a controlled laboratory setting involving one situation. The study did measure the impact of group history, since some members had experienced working together previously. The findings have implications for the use of lean media, in that attention needs to be paid to group cohesiveness especially in more complex decisions where task participation of group members is important.

Even before computer-mediated communication became the status quo, researchers investigated the way technology impacts communication. In 1985, Jablin summarized volumes of previous research on interpersonal communication in task groups. He found consistent indications that the type of task and the type of technology impacted the communication, and more importantly, group members are adaptive in their communication. In other words, group members can adapt their communication to the situation. As research advances with new technologies available in computing, it is evident that group members continue to be influenced by and to adapt to the new forms of technology. Research has investigated the use of groupware as a communication tool for facilitating group decision- 
making and improving task outcomes (Kraemer and Pinsonneault, 1990; Valacich et all, 1993). When completion of tasks is important, group members can adapt to technologies. Rice and Gattiker (2001) conclude that the use of groupware influences outcomes because of "social structures of group processes, tasks and the organization, how groups produce and reproduce their structures through their use and adaptation of technologies, and technical features, limitations and spirit of computer-mediated communication and information systems" (p.561). Thus, the appropriateness and satisfaction of computer-based communication in groups is highly situational and will be based on individual's experiences, the social factors of the group, and the task at hand.

Even theories which attempt to explain communication as a process take variables into account. "Input, process, output theory" (IPO) was established before the advent of groupware or courseware. The theory supports the idea that what happens in a meeting is impacted by the input variables of context. IPO theory considers technology to be an input, along with group and task characteristics (Fulk and Collins-Jarvis 2001). For the foundational work on this theory see Hiltz et all, 1978; Kiesler, et all, 1984; Nunamaker et all,1991; Rice,1984. Some communication scholars have applied the theory to computer-based communication. Although the research comes from organizational communication perspective, it has validity for a study on courseware in classroom settings.

In their work Wired Meetings, Fulk and Collins-Jarvis (2001) give details on the positives and negatives of computer based communications. They note that because communication via commuters tends to be more task orientated, the results should be better and more efficient in making decisions, but with an important caveat. Since groups lack the interpersonal social cues that come with face-to- face communication, groups might end up spending more "...time processing information to analyze their tasks and coordinate their efforts" (p.636) thereby reducing productivity. In addition, the researchers identified two other positive aspects of groups making extensive use of technology. First, the stored record that computerized communication supplies does reduce the loss of information in processing. And second, while it may be easy to tune out a group member's contribution in a face-to-face discussion and disregard the individual's contributions, within courseware the message is a permanent record in the group's discussion area.

It is evident that while media richness theory has validity in situations where face-to-face communication might be optimal because of complexity, computer-mediated communication can also have value for task-based group assignments. It can prompt more participation from group members and allow for group members to have a record of the communication. Because the record is in a written format and can be reflected on and reviewed courseware can be viewed as a tool to facilitate communication, even with the limitation of less social interaction.

Work on the impact of technology on communication spans a number of theoretical perspectives from the social constructivist viewpoint to the type of media used. Many view the social situation as the most important factor in group communication, while others put emphasis on the type of media used to communicate. Context and the variables of group and task characteristics also need to be considered. As technology continues to shape the way groups communicate, there is evidence that computer mediated communication such as courseware can enhance the method groups use to communicate, solve problems, and accomplish tasks.

\section{TECHNOLOGY AND TEACHING METHODS}

Technology continues to change delivery methods for college classes. Instructors need to be aware that some students will benefit from delivery forms that do not require them to come to the main campus. In the scholarship of teaching and learning, researchers have investigated changing delivery methods and the importance of collaborative learning for pedagogy and computer-mediated communication. Clearly, the way students learn is no longer bound by place and time. As technology moves to communication tools that allow for access in a variety of formats at various times, delivery of courses is also changing.

\section{Distance Education}

Distance learning can take place both synchronously via video or audio channel and asynchronously in an online format. Because of the onslaught of online courses being offered and the ensuing pedagogical discussions, 
there is considerable debate over the comparative advantages of the totally online course compared to the hybrid course, which combines online instruction with some face-to-face meetings. Research on distance education in the synchronous format has covered a variety of issues, which include adjusting to technology, participation, and levels of motivation and satisfaction on the part of students.

Considerable research has been conducted in the area of distance education and technology, including studies which have investigated student's lack of familiarity and learning curves for adaptation (Viverias-Dresler and Kutschke, 1992; Gallagher and McCormick, 1999). Others studies have focused on differences between traditional classroom courses and distance course in terms of the outcomes of participation and grades. While not conclusive, these studies appear to indicate that distance education can provide an equivalent opportunity when compared to traditional classroom instruction (Binner, Barone and Welsh, 1997; Poole, 2000; Freddolino and Sutherland, 2000).

Another more definitive study recently investigated a graduate statistics course (Brown and Kulokowich, 2004) comparing a distance class delivered in a synchronous video format to a traditional class taught by the same instructor. The course was used as an experiment to compare skill levels, grades, and responses to the distance format between traditional and distance students. Students who enrolled did not know which format the course would be taught in. There was no significant difference between the distance format and traditional format in grades, group participation, completion of homework, or contact with the instructor. And interestingly, the students in the distance class indicated they would be interested in taking another distance class by a three to one margin when compared to the face-to-face students.

Some work has investigated the reasons students choose a distance course. Often times distance courses are attended by students with specific conditions, which prevent their enrollment in traditional classes. The studies point towards the motivation and unique needs of the non-traditional student who is usually enrolled in a distance course. Angel (2003) found in her research with students at UW-SP enrolled in the Collaborative Degree Program (CDP), typically students are balancing full-time jobs and families in addition to taking the distance courses. The main reasons students opted for the CDP program were proximity and time. Her research also indicated that students in this program feel there is a lack of interaction because of the distance format.

In general, comparisons seem to indicate parity of satisfaction in distance formats in spite of technology issues and learning curves. Main motivators for enrolling in a distance program are time and work constraints. Convenience is a prime consideration for students in distance courses.

\section{Online Formats}

As technology continues to offer more advanced delivery methods, many in the academy have been proponents of online delivery and methods for encouraging student participation in discussions online. Since online classes offer the opportunity for interaction outside the assigned meeting time of the traditional course period, there appear to be more opportunities for students to collaborate outside class when using courseware as a communication tool.

With the explosion of online offerings, many instructors have shared their experiences. One instructor found with the asynchronous format in which students used a threaded discussion, there were substantially more opportunities for all students to participate. Those that might not speak up in class are required to post discussion responses, thereby ensuring active participation. However, this same instructor voiced concern about the lack of "inthe-moment" or live presence, and noted that as the discussion moves forward some students can get left behind (Chisamore, 2004). Other instructors point out that the principles of good teaching, active learning, time on task, and organization of information in an easy to remember format, are key principles for teaching, whether online or in the traditional format (Diamond, 1998).

Other studies (Anderson and Kanuka, 1997; Wright, March and Miller 2000; Burke, 2001; Timmerman, 2004) produced mixed results from student responses when comparing methods of delivery. Generally, it appears that 
while students perceive social presence to be more limited in online formats, they also agree that the quality of discussion can be high. Some studies also indicate parity in outcomes of grades when comparing the methods.

A recent study involved an online communication course which was used as an experimental combination of audio and video lecture materials on $\mathrm{CD}$. Comparisons were made through survey methods and in student performance. Timmerman (2004) found that students preferred the "richer" type of instruction delivery in a recorded video on $\mathrm{CD}$ over the audio format. He also found no significant differences in the learning outcomes, measured in quizzes and in self-reports between the formats. He measured instructor/ student familiarity and found significant differences, with more familiarity in the video format. However, this study does not take into account any type of interaction between the students through computer mediated group communication.

Similar results were found by Wright, March and Miller (2000) who determined via a survey of students enrolled in a graduate level technology course that there was no significant difference between asynchronous and synchronous course offerings in learning or evaluation. Interestingly, the asynchronous students' response to one of three questions about course satisfaction was the only significant difference between the two methods of delivery. When asked to rate the value of the learning experience, the online response ratings were higher. The researchers attempted to explain this higher rating as a result of a perception on the part of the online students that the instructor was more available in the online format, with more access as compared to face-to-face course meetings or on campus office hours for traditional courses.

Perhaps the most applicable research comes from a study done in an accounting course, which used group problem solving methods via computer-based communication. The study compared computer-based group support systems in a distance course to a face-to-face course which also used computer-mediated communication in addition to face-to-face communication. Burke (2001) found significant difference in measuring for social presence and participation between the two delivery methods. The face-to-face course group members rated perceived social presence in their group higher than the distance course groups. The level of participation in the face-to-face course was also higher. However, this study has limitations because it collected data only for two consecutive days and did not measure participation over time.

Conversely, other research reveals a lack of opportunities for social interaction in courses taught online. Anderson and Kanuka (1997) found that participants noted a lack of social interactions as well as problems with interpretation of meanings in the online format. Still other studies (Dozier, 2001; Romeo, 2001) have shown that discussions were limited in online formats. In particular, Dozier noted that students lacked the social clues that are important in face-to-face communication.

Some researchers have found that the online method actually improved communication related to course objectives and assignments. A study by Curtis and Lawson (2001) which used a coded analysis of student's postings to a course website over the term, demonstrated evidence of collaboration among the online students. The analysis indicated task-type behaviors of planning and making contributions as being significant. Students also solicited communication from their peers in messages that sought other's input, feedback, and help. And a recent qualitative study (Meyer, 2003) found in comparing online to face-to-face graduate classes, that more time was spent on course objectives in the Internet classes, noting the online students thought they had more time for clarification and research in the online setting than the face-to face students.

While not measuring social presence or media richness, others have investigated communication in online settings as compared to audio-video delivery. An applicable study compared a number of distance courses taught in audio-video format to Internet courses. These courses were taught in a variety of locations with different instructors, making it hard to control variables. However, Landis (2001) found in her qualitative analysis that instructors reported higher quality interactions and communication to be "deeper and denser" (p.19) among the students in the online courses.

Clearly, the results are mixed as to what students perceive in online settings. The research results vary based on course content and the skills of the instructor. And different disciplines impact how the topic is analyzed. Many 
studies have been conducted, but because each class is unique, it is difficult to replicate the studies to empirically test the evidence. However, as online teaching continues to be a method in which instructors attempt to involve students in the learning process through collaboration, it becomes important for continuing research to better understand the group process and students' perception of the collaboration process in online settings. Few studies measure both social interactions and group task outcomes over the length of the term. There is a need for such a study using a comparative analysis between an online and face-to-face format conducted over time.

\section{Hypotheses}

Based on the literature from cooperative learning, communication and group problem solving, communication and technology, three hypotheses were drawn.

\section{Hypothesis 1}

Groups meeting face-to-face will perceive a higher level of social presence in their groups than the online student groups. With the opportunity to meet in class twice a week for 15 weeks as compared to three face-to-face meetings of the online students, it is likely that the face-to-face students will develop higher levels of social interaction.

\section{Hypothesis 2}

Students using courseware will be more task orientated than the students working in the face-to-face groups. Because students are forced to communicate in a written document and are required to respond to each other postings, the online format should result in a higher focus on the assignments or tasks.

\section{Hypothesis 3}

Overall, there will be a positive correlation between group cohesiveness and task orientation. If students are working toward a goal together and are able to complete the task as a group, their perception of getting the task done correlate positively with their perception of the group cohesiveness.

\section{METHODOLOGY}

This research centered around a business course that was taught in the spring term of 2005, with two sections in the traditional face-to-face setting and the other sections taught as an online distance class. For the purpose of this study, the course is described as two classes, one traditional or face-to-face and the other distance online. Management Information Systems, Business 370, is required for all business majors, and students typically have completed about 9 credits in the major before taking the course. The distance course and the face-to-face course cover the same content, and both use a collaborative learning pedagogy through the use of small groups.

Students were grouped alphabetically with five to seven members per group, with six to eight groups per class. Care was taken to avoid grouping students together who had previously worked in groups with each other, to prevent confounding the variable of group history in the study. Grouping took place the first day of class, and students were required to come up with a group contract by the second week of class. It is important to note that students in the distance course were grouped according to their location at each site to facilitate the logistics of presentations for the group project.

Students were given guidelines on developing a contract, and each group was required to develop its own contract to be signed by all members. This contract served the purpose of a charter, which set the course for the group to function as a team. It validated the reason for the team's existence, and helped the team set objectives and deal with behavior issues. According to Southard (1993), "A team charter consists of a core purpose, team management, and behavior standards." (p. 4). In this course, the contract acts as an agreement, which became the focus of common objectives and a results-based orientation. Members developed the agreement themselves, so there was a sense of ownership and shared vision among members from the onset. The challenge in teaching a distance course is to help 
students develop this shared vision and sense of ownership similar to what takes place in the traditional classrooms setting.

The Collaborative Degree Program (CDP) serves students from three locations about 40 miles apart and is considered a distance course. The distance course or the CDP course, met face-to-face only five times in the term. The first class meeting was set up as an introduction and group assignment time. During the first meeting period, students were required to begin work on a group contract. Students met twice in person for exams and for delivery of course material via instructional videos. The final two weeks of class were reserved for student presentations in the CDP, while the presentations in the face-to-face class took place each week beginning in the eighth week. Students in the CDP class were not required to meet in their groups, face-to-face outside the first class meeting. Their primary means of communication was expected to be through courseware. However, since students were put into groups at their own location, if they wanted to meet in person, they had close proximity to do so.

To avoid confounding of variables all discussion questions, assignments, and exams were the same for both classes. Group communication involved weekly discussion around a topic related to the course content and a group research project. This major research project was assigned to be presented in PowerPoint format, and all groups were required to present their findings to the class toward the end of the term. The major difference between the classes was that the face-to-face classes were required to meet each week in class in groups and to work on their discussion questions. The online class was required to meet only for the first meeting and for the final presentations. In person exams were given on two nights in the online class, but students were not required to meet in their groups. Group meetings in the online class were optional. Students in the distance class had discussion boards set up for their individual groups within the Desire to Learn web site. For the distance class, lecture material was typed and posed in the content area, whereas the lectures in the face-to-face class were given in person. Additionally, both classes had access to chapter notes in PowerPoint. The students in the face-to-face class met in class each week to work on their discussion questions as part of the weekly topic coverage, while the Collaborative Degree Program (CDP) students were required to post individual responses to a question followed by a threaded discussion of group members' responses.

It was important for groups to acclimate in working together and to begin to focus on the group contract and the group project early in the course. The weekly assignments ranged from lower level work, which required simple descriptions using terminology to higher level thinking assignments such as case studies, which required a clear definition of the problem and decision-making skills. The weekly assignments accounted for 15 percent of the students' grades and the group project accounts for another 15 percent of the grade. Participation accounted for 10 percent of the grade, and participation points were allocated by peer members. Thus, students had a vested interest in making things work in their groups, since a total of 40 percent of their grade rested on cooperative efforts.

Students in the face-to-face class met the typical profile of the student population at UW-SP and are usually Business Administration majors or minors. Students enrolled in the CDP class were typically non-traditional students, either working full time or returning to college after an interruption. CDP students could be either Business Administration or General Studies majors.

In the attempt to better understand the role technology played in group effectiveness, the survey was designed to investigate the students' perceptions of social presence, group cohesiveness, and task orientation in semester-long small groups. Social presence as defined by Burke (2001) is defined "as the extent to which an individual is thought of as being real during computer-mediated communication" (p.3). The questions developed to measure social presence were adapted from the revised Social Presence Instrument (Chidambaram and Jones, 1993), which has been used in past computer-mediated communication studies (Burke). Additionally, questions to determine how group members perceived their group's cohesiveness and attention to tasks were added. Group cohesiveness simply refers to a person's attraction to a group (Yoo, and Alavi, 2001). These questions were adapted from the Group Attitude Scale developed by Evans and Jarvis (1986) which also has been used in computer-mediated communication studies. The format of the survey was a five point Likert type scale with responses ranging from strongly agree to strongly disagree. Students were asked to assign a numeric value to each answer, thereby making statistical analysis possible. Regression analysis was used to determine if statistically significant differences were apparent. 
The survey was administered in both classes during the last week of the term. The first question identified group numbers. Questions two through six measured social presence, questions seven through eleven measured group cohesiveness, with question nine being the strongest measure of group cohesiveness. Questions twelve through sixteen measured task orientation. Question eighteen applied only to the online class, asking students to rank their feeling regarding electronic media as a substitute for face-to-face communication. Question nineteen asked students to predict their grade on the group assignment. Questions twenty and twenty-one looked at the amount of time spent on the project individually and as group. Lastly, an opened question was included to allow students to describe their group experience. This qualitative information was gathered to obtain a more in depth understanding of the experience and will be used in a future study.

\section{SURVEY}

Please indicate by number your perception of your group experience in this class. Please use the following scale to determine if the statement matches what you think. Scale:5 strongly agree, 4 agree, 3 neutral, 2 disagree, 1 strongly disagree.

1. My group number is

2. I feel connected to my group.

3. We shared ideas in my group

4. My group members were able to express themselves.

5. I got to know people in my group.

6. My group members cared about each other.

7. I felt involved with what my group accomplished.

8. Different points of view were accepted in my group.

9. I would have switched groups if I could.

10. I care what happens in my group.

11. My absence from the group would make a difference.

12. My group members completed tasks as we agreed.

13. The input of others in my group helped with the work.

14. As a group we accomplished more that I would on my own.

15. Our group decisions were based on mutual input.

16. My group met the goals I expected.

17. My group number is

18. I felt the use of electronic media via D2L or e-mail was an adequate substitute for face-to-face communication between group members

19. I feel my group will get this letter grade on our presentation.

20. Please list the number of hours you spent individually on the group project

21. Please list the amount number of hours your group spend meeting in person on the project

22. Please briefly describe your group experience in this class.

To meet the requirement of the Institutional Review Board, a form advising students of their right to refuse to participate in the survey was included with the survey.

\section{FINDINGS}

This section details the findings, and a discussion follows with recommendations for educators using small groups and online teaching methods. The recommendations point to specifics educators can use to enhance communication within small groups. 


\section{Results}

\section{Hypothesis 1}

It was anticipated that those groups meeting face-to-face would perceive a higher level of social presence in their groups than the online student groups. Because the traditional students had the opportunity to meet in class twice a week for 15 weeks as part of the class meeting times, it was expected that the face-to-face students would develop higher levels of social interaction. Questions two through six were used to measured social presence. For all operational definitions of social presence, or the feeling of being 'real' during communication, the data did not support a difference in social presence between the groups since there was not a statistically significant difference in responses between the classes.

Table 1: Difference In Mean For Social Presence

\begin{tabular}{|l|c|c|c|c|c|}
\hline Question \# & Face-To-Face & Online & Diff. in Mean & Std. Error & P Value \\
\hline 2 connected & 4.21 & 4.25 & .04 & .1793 & .7960 \\
\hline 3 share ideas & 4.64 & 4.52 & .12 & .1382 & .3651 \\
\hline 4 express & 4.46 & 4.64 & .18 & .1634 & .2645 \\
\hline 5 know & 4.23 & 4.32 & .09 & .2017 & .6502 \\
\hline 6 care about each other & 4.09 & 4.09 & 0 & .2067 & .9976 \\
\hline
\end{tabular}

Questions seven through thirteen were developed to measure group cohesiveness or a person's attraction to the group. Although there was no prediction made regarding differences between the classes in regard to group cohesiveness or attraction to the group, it does seem consistent that groups that score high in social presence would also score high in group cohesiveness. Not surprisingly, the data showed no significant differences in group cohesiveness between the two classes.

Table 2: Difference In Mean For Group Cohesiveness

\begin{tabular}{|l|c|c|c|c|c|}
\hline Question \# & Face-To-Face & Online & Diff. in Mean & Std. Error & P Value \\
\hline 7 involved with accomplishments & 4.56 & 4.77 & .21 & .1339 & .1100 \\
\hline 8 different pts of view & 4.38 & 4.54 & .16 & .1746 & .3512 \\
\hline 9 switch groups & 1.55 & 1.45 & .10 & .1791 & .5555 \\
\hline 10 care what happens & 4.54 & 4.58 & .04 & .1345 & .7547 \\
\hline 11 absence from group & 4.15 & 4.38 & .23 & .1784 & .1950 \\
\hline
\end{tabular}

\section{Hypothesis 2}

It was predicted that students using courseware would be more task orientated than the students working in the face-to-face groups. Questions twelve through sixteen pertained to task. This hypothesis was also not supported by the data. There were not statistically significant differences in the responses on questions related to task.

Table 3: Difference In Mean For Task Orientation

\begin{tabular}{|l|c|c|c|c|c|}
\hline Question \# & Face-To-Face & Online & Diff. In Mean & Std. Error & P Value \\
\hline 12 completed tasks & 4.59 & 4.64 & .05 & .1546 & .7521 \\
\hline 13 others input helped with work & 4.51 & 4.54 & .03 & .1484 & .8448 \\
\hline 14 accomplished more as a group & 4.53 & 4.41 & .12 & .1860 & .5239 \\
\hline 15 mutual input/decisions & 4.55 & 4.58 & .03 & .1389 & .8692 \\
\hline 16 group goals & 4.55 & 4.45 & .10 & .1604 & .5104 \\
\hline
\end{tabular}




\section{Hypothesis 3}

Overall, it was expected there would be a positive correlation between group cohesiveness and task orientation. Question nine "I would have switched groups if I could" was used as the strongest measure of group cohesiveness to test hypothesis three. A correlation test between question nine and the questions related to task, numbers twelve through sixteen, was run. The data did support this hypothesis. Reverse scoring of question nine resulted in positive correlations at the 95 percent confidence level, between question nine, (switch groups) and questions twelve (completed tasks) thirteen (other's input helped) and sixteen (group goals) for both classes. Question nine (switch groups) and fourteen (accomplished more as a group) did not have significant correlation for the online class with the correlation coefficient being .1001 with a $\mathrm{p}$ value of .5922 . While question nine (switch groups) and fifteen (group goals) did not have a significant correlation at the 95 percent confidence level for the face-to-face class, with the correlation coefficient at .2724 and the $p$ value at .0507 there was correlation at the 90 percent confidence level.

Table 4: Correlation Between Group Cohesiveness And Task Orientation

\begin{tabular}{|l|c|c|c|c|}
\hline $\begin{array}{c}\text { Correlation With Question 9 } \\
\text { Switch Groups }\end{array}$ & $\begin{array}{c}\text { Online } \\
\text { Correlation Ratio } \\
\text { (Pearson's r) }\end{array}$ & P Value & $\begin{array}{c}\text { Face-To-Face } \\
\text { Correlation Ratio } \\
\text { (Pearson's r) }\end{array}$ & P Value \\
\hline 12 completed tasks & .4896 & .0052 & .6492 & .0000 \\
\hline 13 others input helped with work & .4294 & .0159 & .4822 & .0003 \\
\hline 14 accomplished more as a group & .1001 & .5922 & .5397 & .0000 \\
\hline 15 mutual input/decisions & .4877 & .0054 & .2724 & .0507 \\
\hline 16 group goals & .5683 & .0009 & .6201 & .0000 \\
\hline
\end{tabular}

Furthermore, there was no significant difference between the classes in the expected grades on group presentations for question nineteen. The average grade students expected to receive in both the online and face-to-face class was 3.8, slightly lower than an A.

Only students in the online format were asked to respond to the question regarding electronic media, question eighteen. "I felt the use of electronic media via D2L or email was an adequate substitute for face-to-face communication." The responses from these students offer insights. 32 percent of the students in the online class strongly agreed, and 17 percent agreed that D2L or online communication was an adequate substitute for face-to-face communication. However, 26 percent strongly disagreed and 13 percent disagreed, with the reminder neutral. Thus, 49 percent of the students in the online setting did view electronic communication as an adequate method of communication compared to face-to-face communication. However, it is worth noting that the online students chose to spend a considerable amount of time meeting face-to-face as well as online.

Students in the online class reported that they spent considerably more time on the project both individually and as a group than the face-to-face groups. On average, time reported working individually on the project was 12.2 hours outside class, as compared to 4.9 hours for the face-to-face students. Furthermore, the online class reported about 40 percent more time spent working together as a group on the project than the average for the face-to-face groups. The 9.1 hour average was reported by the online students as compared to 6.3 from the face-to-face students. The commitment of the online students to both work independently to contribute to the group project and meet in person even through they were not required to do so may explain why there was no difference in hypothesis one and two.

Table 5: Time On Project By Type Of Class

\begin{tabular}{|c|c|c|}
\hline Question \# & Face-To-Face & Online \\
\hline 20 average time spend individually & 4.9 & 12.2 \\
\hline average time group members reported working as a group on the project & 6.3 & 9.1 \\
\hline
\end{tabular}


Question twenty-two asked students to briefly describe their group experience. Responses were sorted into positive, negative, and neutral categories. A numeric value of two was used for a positive response, one for a neutral response, and zero for a negative response for categorization. The online class had two negative responses out of 29. In the traditional class, there were no negative responses out of 47 responses. Typical positive descriptors included "good", "learned a lot," and "worked well together." The negative descriptors included "difficult" and "didn't make us learn anything." "Okay" was typical the word used for neutral responses.

Table 6: Description Of Experience By Class Type

\begin{tabular}{|l|c|c|}
\hline & Online & Face-To-Face \\
\hline Total number of responses & $29 / 31$ & $47 / 52$ \\
\hline Positive responses & 21 & 42 \\
\hline Neutral Responses & 6 & 5 \\
\hline Negative Responses & 2 & 0 \\
\hline
\end{tabular}

*2 students did not answer. * 5 students did not answer

In summary, there was essentially no difference between the online class and the face-to-face class in the questions regarding social presence, group cohesiveness, and orientation to the task. As expected, for the most part there was correlation between group cohesiveness and orientation to the task. The discussion section offers possible explanations.

\section{Discussion}

While the data did not support the first two hypotheses, we can gather some valuable insights from the results. Three deductions can be drawn from the research regarding small group communication. First, over time within small groups, social presence and group cohesiveness develop together. Second, students are adaptive in their communication methods within groups. Third, with adequate support, students in small groups will organize and communicate around the task, positively reinforcing group cohesiveness.

A fifteen week course gives students the opportunity to get comfortable with each other. In the span of the course, groups were required to work on tasks that helped build their confidence, moving from simple discussions to the more complex task of the group project. It is evident that during this time span both social presence and group cohesiveness were built.

It is clear that relying solely on computer-mediated communication was not the desired method of communication for the online students. Perhaps in a totally online environment where students were not able to meet face-to-face, results might show significant differences. The fact that the groups in the online class decided to meet on their own throughout the term, combined with the ability to connect with each other online each week though courseware, clearly influenced both social presence and group cohesiveness. In fact, the online students spent on average more hours meeting in groups outside of class than the face-to-face students. The high levels of social presence and group cohesiveness found in the online groups may have influenced the student's desire to meet in person. Most likely, the desire to meet in person was also influenced by other factors not accounted for in this study, primarily the demographic profile of the Collaborative Degree Program (CDP) student.

Conversely, an argument can be made that students in the CDP or online format opted to meet in person to establish social presence and group cohesiveness before tackling the project which was due at the end of the term. As noted previously, this project was highly complex and required a significant amount of decision-making and problem solving. The desire to meet in person to 'hash things out' would support the original work by Daft and Lengel $(1984,1986)$ that situations in which tasks are not clear and problems are complex, relying solely on commutermediated communication can impede the communication process. While computer-mediated communication helped to facilitate completion of tasks once major decisions were made, social presence and group cohesiveness was 
established by meeting in person. While students did make use of electronic communication to facilitate their work, they were motivated to meet on their own.

Meeting in person is particularly important in the early stages of group development. Certainly, introducing the contract in the first meeting period facilitated group development in both classes. Past research has indicated that the group contract paves the way for cooperation among group members (Mihm, 2004). Once online students committed to each other via the group contract, they decided to meet regularly even through they were not required to do so. These initial group meetings allowed students to formulate plans, assign tasks, and organize their work on the project. Accomplishing small tasks early on in the group development process contributes to and self-confidence and self-efficacy for the group. For example, once students accomplished the task of setting up their group contracts, their ability to work together was confirmed. This confidence in what the group feels they can achieve is positively reinforcing, giving them more confidence as time goes on.

Students in the online class used multiple forms of communication to work together. They met in person, they used cell phones, they used courseware, and e-mail to facilitate their work. Students used technology as a communication tool to assist in their completion of tasks. This is clear from the number of postings in the discussion section and the responses group members made to each other, documented in the D2L site. In the 20 years after the work of Jablin (1985) regarding groups and media choice, we continue to see adaptive communication strategies on the part of groups regarding technology. Because students did meet face-to-face the use of electronic media should be viewed as a supplement to the time they spent in person.

Students unquestionably organized themselves and communicated around the tasks assigned to their groups. Meeting in person to facilitate the completion of the group project definitely factored into the group meetings. The CDP students spent more hours working on the project than the face-to-face students. I believe this is the main reason why there were not differences in social presence or group cohesiveness between the online class and the traditional class. The stakes for the success of the group on the project were fairly high, since the project was 15 percent of the students' grade and this influenced their desire to meet. Moreover, the online course was scheduled in the timetable for a regular meeting time. Therefore, students did not have a time conflict if they decided to meet during the scheduled period. Additionally, since the groups had to present their research to the class there was an element of peer pressure that impacted cooperation.

There was a lack of correlation between question nine (switch groups) and question fourteen "As a group we accomplished more than I would on my own" for the online class. This indicates that some of the online students thought they could accomplish more on their own. The two negative responses from the online students on the openended questions regarding the small group experience confirm this. Perhaps while not being dissatisfied with their group for the weekly discussion portion of the course, the online students, who were non-traditional students, would have preferred an individual project where they would be graded on their individual work. The average individual time spent on the project was 12.2 hours as reported by the online students, more than twice the average amount of time reported by the traditional students 4.9. Most likely the additional time spent was a factor in the lack of correlation for this question. And again, demographic factors may be influencing the difference. The CDP students may be more motivated to work both independently and as a group to produce a quality project. Work experience, levels of maturity, and reason for taking the class are all variables unaccounted for.

In the face-to-face class, the correlation between the switching groups question and question fifteen regarding group decisions based on mutual input was not as strong as the correlation on the other task questions. This may indicate that decisions were not made by all members in a few groups and may point to a number of controlling individuals within a few groups, or a number of slackers in a few groups.

\section{Limitations}

An important point that should be considered is that this study did not attempt to measure the demographic profile of the CDP students, those using the online format as compared to the traditional students. My past experience in teaching the non-traditional students in the CDP has been that students are highly motivated, focused on 
assignments, and concerned about grades. Some students in the CDP already have a bachelor's degree and are taking the business courses to get into MBA programs. Additionally, many of the students are working in job settings that require group interaction, giving them practical experiences on how to work with others towards the completion of a project. Finally, as Angel (2003) noted in her qualitative study with the CDP population, students indicated there is a lack of interaction in the distance format. If in fact students did feel the distance format lacked interaction, then meeting in person even if not required would seem logical.

While the response rate was high with 52 of 55 (95 percent) of the face-to-face students responding and 31 out of 33 (94 percent) of the online class responding, it should be noted that the self-report survey has limitations. In particular, there are problems with generalizing from a study in the classroom. Situational variables such as subject matter, instructor style, and group members' personalities, are difficult to control. Perhaps even the fact that I administered the survey impacted the responses. And certainly, self-reported responses are limited to self- perceptions assuming individuals are both self-aware and honest in their responses.

\section{Conclusions}

The purpose of this study was to compare student perceptions of collaborative group work in the traditional face-to-face class setting compared to a hybrid class setting using courseware, or Desire to Learn. Because the hybrid or online students opted to meet in person throughout the semester, no significant differences were found on questions regarding social presence and group cohesiveness between the classes. The data did support a strong correlation between group cohesiveness and task orientation for both types of classes. While anecdotal observations found discussion to be more in-depth in the online setting, the students in the hybrid class were split on the question regarding online communication as a substitute for face-to-face communication.

Despite the limitations, there are some important conclusions that can be drawn for educators. Previous study has clearly shown that group pedagogies which build cooperation can enhance learning. As Palloff and Pratt (2001) point out, building collaboration into online courses helps produce the outcomes of "knowledge and deeper levels of meaning" (p.115). New communication technologies such as courseware, allow students to improve their collaborative efforts by making better use of resources such as time and the sharing of information. However, it is apparent that given the opportunity, students may prefer to use face-to-face communication, especially when the task requires many details to be worked out. This goes along with giving students the freedom to develop their strategy for working in groups. The group contract sets the stage for collaboration, but students need to hammer out their differences and work through the details of the project, including whether in person meetings are useful. Palloff and Pratt note the instructor needs to give up control and step out of the way during collaborative assignments.

The group development process is messy and non-linear, and rests on the group's ability to establish social presence, group cohesiveness, and orientation to the task. Because the group development process occurs over time, it is very important to set the stage for cooperation early and to allow sufficient time for large group projects to be completed. Allowing students to self-organize around the task will occur more easily when students feel committed to the group. Social interaction clearly impacts group cohesion. According to Palloff and Pratt, totally online courses should provide for methods of informal socialization and support. Because the online course in this study did not offer an area for this informal support, it appears the students used an in person method to get to know each other and build group cohesiveness.

It is evident that computer-mediated communication can enhance the completion of tasks in classroom situations. Since the traditional class did not use courseware for their weekly discussion, there is no way to actually compare the type of communication that took place. However, in my field notes, I made anecdotal observations of students in the face-to-face course reporting summaries of their discussions to the class. In comparing verbal reports to the online postings, I observed that the online discussion was more thorough. Student postings were more thought out. Students took more time to link the discussion to the text and lecture material. The online discussion involved more back and forth communication between group members. I would agree with Landis (2001) comment that the level of communication seemed to be "deeper and denser" in online settings. Because part of the requirement for online postings was that students needed to respond to another's comments, the online communication was more intense as 
compared to the face-to-face communication which often seemed to be superficial or contrived. I believe because students were forced to read and respond to each other's ideas in the online setting, the communication moved to a higher level and helped students feed off each others ideas This observation supports the work of Curtis and Lawson (2001) who found evidence of high levels of collaboration in the online postings. Moreover, students knew that I had a record of the discussion in the online format. In the traditional class, verbal communication during class time was difficult to capture. It was hard to know if students were getting off track and if all group members are participating.

\section{Future Research And Recommendations}

Future research could take a number of paths. The D2L site for the class captures a rich history of the weekly group discussion on which content analysis could be used. Future research could also explore the correlation between time spend and actual grades on the projects. This study was limited to small group communication and computermediated communication. Continuing research for online courses using courseware should investigate overall satisfaction in relation to the learning objectives.

Further research on the demographic profile of the CDP students would be very useful in exploring which types of pedagogies should be used to deliver courses for distant learning. Combinations of online and face-to-face delivery can provide more flexibility and finding out how these combinations might meet students scheduling needs while continuing to increase student learning would be useful. Assessments to determine if there are differences in learning between online and face-to-face course would also be helpful.

Overall, the way students in the online class came together surprised me. It was interesting to see the groups develop as the term went on. It was helpful to learn the value of using courseware as communication tool for the groups. I feel it did contribute positively to higher levels of discussion. It certainly did organize the material for the students, which I think helped add to their commitment to the course.

In conclusion, there are four recommendations that can be made for educators using groups based on the literature review and research. Since this project was an extension of my work as a Wisconsin Teaching Fellow, in which I was able make a connection between the group contract and group cohesiveness these recommendations do not rest solely on the current study. However, the findings from this study confirm much of the research on cooperative learning and group communication.

First, instructors should structure classes to facilitate communication between group members in both online and face-to-face settings right from the very beginning of the course. A good way to do this is by having students develop a contract. Part of this first step should be to allow students to socialize, either online or in person, to build social presence and group cohesiveness as noted by Palloff and Pratt (2001). Second, instructors should step out of the picture once the assignment is given and allow students to self-organize around the task. However, while it is important to give control to students, instructors need to be willing to point groups in the right direction if questions come up. Instructors really should take a behind the scenes presence. Third, instructors should make sure to allow for sufficient time for groups to come together and accomplish their tasks. Because the group development process is non-linear, giving groups time to sort through problems is essential. Adding low-stake assignments in the beginning to build group cohesiveness is also important. Fourth, instructors should consider using courseware to facilitate communication, even in traditional, face-to-face courses. Because it provides a written record of participation, it seems to assist group members in moving to more complex and thorough communication.

As new technologies impact pedagogies, the principles for cooperative learning remain. The media used for groups to communicate and work on tasks can take different forms, but the results should reinforce positive interdependence based on mutual commitments. No matter which medium is used, instructors who set their courses up to facilitate collaboration will find that students tend to get more out of the material and usually find the group experience a positive one.

The authors acknowledge the support of the University Personnel Development Committee. 


\section{REFERENCES}

1. Anderson, T. \& Kanuka, H. (1997). On-line forums: New platforms for professional development and group collaboration. Journal of Computer-Mediated Communication. 3(3).

2. Angel, C. (2003). A Central Wisconsin Collaborative Degree Program. Thesis- MA in Communication. UWStevens Point, WI.

3. Bales, R. F. (1951). Interaction Process Analysis. Addison-Wesley. Reading, MA.

4. Bandura, A. (1991). Social cognitive theory of self-regulation. Organizational Behavior and Human Decision Process. 50. 248-287.

5. Bartol, K. \& Martin D. (1998) Management. McGraw Hill. New York, NY.

6. Bateman, T. S. and Snell, S. A. (2004). Management: The New Competitive Landscape. McGraw-Hill. New York, NY.

7. Bilimoria, D. \& Fukami, C. (2002). The scholarship of teaching and learning in the management sciences. In Disciplinary Styles in the Scholarship of Teaching and Learning Eds. Huber, M, Morreale, S. American Association for Higher Education. Washington D.C., 125-142.

8. Binner, P. M., Barone, N., \& Welsh, K. (1997). Relative academic performance and its relation to facet and overall satisfaction with interactive telecourses. Distance Education. 18, 318-326.

9. Brown, S. W. \& Kulikowich, J. M. (2004). Teaching statistics from a distance: What have we learned? International Journal of Instructional Media. 31(1), 19-34.

10. Burke K. \& Chidambaram, L. (1999). How much bandwidth is enough? A longitudinal examination of media characteristics and group outcomes. MIS Quarterly 23(4), 557-580.

11. Burke, J. (2001). Collaborative accounting problem solving via group support systems in a face-to-face versus distant learning environment. Information Technology Learning and Performance Journal. 19 (2) 1-19.

12. Carlson J. R. \& Zmud R. W. (1999). Channel expansion theory and the experiential nature of media richness perceptions. Academy of Management Journal. 42(2), 153-170.

13. Chidambram, L. \& Jones, B. (1993). Impact of communication medium and computer support on group perceptions and performance: A comparison of face-to-face and disperses meetings. MIS Quarterly, 17 (4) $465-491$.

14. Chisamore, D. (2004). Structuring the case method for asynchronous online learning. Online Classroom. June, 2004 1-2.

15. Cohen, S. \& Bailey, D. (1997). What makes teams work: group effectiveness from the shop floor to the executive suite. Journal of Management, 23 (3), 239-290.

16. Contractor, N. \& Eisenberg, E. (1990). Communication networks and new media in organizations. In Fulk, J and Steinfeld, C. (eds), Organizations and Communication Technology. Sage, Newbury Park, CA, 143-172.

17. Curtis, D. D. \& Lawson, M. J. (2001). Exploring collaborative online learning. JALN.5 (1), 21-34.

18. Daft, R. L. \& Lengel, R. H. (1984). Information richness: A new approach to managerial behavior and organizational design. In Research in Organizational Behavior (6) (eds). Staw, B and Cummings, L. JAI Press Greenwich, CT, 191-233.

19. Daft, R. L. \& Lengel, R. H.(1986). Organizational information requirements, media richness, and structural design. Management Science 32, 554-571.

20. Dennis, A. R. \& Kinney, S. T. (1998). Testing media richness theory in the new media: The effects of cues, feedback and task equivocality, Information Systems Research. 9(3), 256-274.

21. Diamond, N. (1998). Adding on-line computer methods to your repertoire of teaching strategies. Teaching Excellence: Toward the Best in the Academy. POD Network. North Miami Beach, FL. 9 (6), 1-2.

22. Dozier, K. S. (2001). Affecting education in the on-line "classroom": The good, the bad and the ugly. Journal of Interactive Instructional Development. 13 (4), 17-20.

23. Evans, N. \& Jarvis, P. (1986). The group attitude scale: A measure of attraction to group. Small Group Behavior. 17 (2), 203-216.

24. Felder, R. M. \& Brent, R. (1994). Cooperative learning in technical courses: Procedures, payoffs, and pitfalls. Eric Documentation Reproduction Service Report. ED 377038.

25. Fisher, B. A. (1970). The process of decision modification in small groups. The Journal of Communication. 20, 51-64. 
26. Freddolino, P. P. \& Sutherland, C. A.( 2000). Assessing the comparability of classroom environments in graduate social work education delivered via interactive instructional television. Journal of Social Work Education. 36,115-129.

27. Fulk, J. (1993). Social construction of communication technology. Academy of Management Journal. 36(5), 921-950.

28. Fulk, J. \& Collins-Jarvis, L. (2001). Wired meetings. in The New Handbook of Organization Communication (eds.) Jablin, F. M and Putnam, L. L. Sage, Thousand Oaks. CA, 544-581.

29. Gallagher, P. A. \& McCormick, K. (1999). Student satisfaction with two-way interactive distance learning for delivery of early childhood special education coursework. Journal of Special Education Technology. 14, $32-47$.

30. Gersick, C. J. (1988). Time and transition in work teams: toward a new model of group development. Academy of Management Journal. 31(1), 9-41.

31. Gouran, D. S., Hirokawa, R. Y. Julian, K. M., \& Leatham, G. B. (1993). The evolution and current status of the functional perspective on communication in decision-making and problem-solving in groups.

Communication Yearbook. 16, 573-600.

32. Haag, S., Cummings, M., and McCubbrey, D. (2004) Management Information Systems. McGaw-Hill New York, NY.

33. Hiltz, S. R., Johnson, K., \& Agle, G. (1978). Replicating Bales’ problem-solving experiments in a computerized conferencing system. (Research Report 8). New Jersey Institute of Technology, Computerized Conferencing, and Communication Center. Newark, NJ.

34. Hirokawa, R. Y. (1982). Group communication and problem-solving effectiveness I: A critical review of inconsistent findings. Communication Quarterly. 30(2),134-141.

35. Hollingshead, A. B \& J. E. McGrath (1995). Computer-assisted groups: A critical review of the empirical research. In Team Effectiveness and Decisions Making in Organizations. (eds) Guzzo, R.et all. Jossey-Bass, San Francisco, CA, 46-80.

36. Jablin, F. M. (1985).Task/Work Relationships: A life span perspective. In Handbook of Interpersonal Communication, (eds.) Knapp, M. L. and Miller, G. R., Sage. Beverly Hills, CA, 615-654.

37. Johansen, R. (1988).Computer Support for Business Teams. Free Press. New York, NY.

38. Johnson, D., Johnson, R., \& Smith, K. (1991) Cooperative learning: Increasing college faculty instructional productivity. ASHE-ERIC Higher Education Report, No. 4. The George Washington University. Washington DC, $1-10$.

39. Keer, E. \& Hiltz, S. R.(1982). Computer-Mediated Communication Systems: Status and Evaluation. Academic Press. New York, NY.

40. Kiesler, S., Siegel, J., \& McGuire, T. (1984). Social psychological aspects of computer-mediated communication. American Psychologist. 39,1123-1134.

41. Kraemer, K. \& Pinsonneault, A. (1990). Technology and groups: assessments of the empirical research. in intellectual teamwork. In Social and Technological Foundations of Cooperative Work (eds.) Galegher, J. and Kraut, R. and Egido, C. Lawrence. Erlbaum. Hillsdale, NJ, 373-404.

42. Landis, M. (2001), A comparison of interaction in AV-based and internet-based distance courses.

Educational Technology and Society. 4 (2). 1-19

43. Lawler, E. E. (1999). Employee involvement makes a difference. Journal for Quality and Participation. 22(5), 18-20.

44. Lee, A. S. (1994). Electronic mail as a medium for rich communication: An empirical investigation using hermeneutic interpretation. MIS Quartlerly. 18(2), 143-157.

45. McGlynn, A. P. (2001). Successful Beginnings for College Teaching. Atwood Publishing. Madison, WI.

46. Meyer, K. A. (2003). Face-to face versus threaded discussions: The role of time and higher-order thinking. JANL .7 (3), 55-65.

47. Mihm, B (2004). Using a Contract to Enhance Performance in a Management Course. The North American Management Society Proceedings, Chicago IL.

48. Millis, B. (2001). Cooperative learning: It's here to stay. Teaching Excellence: Toward the Best in the Academy. POD Network. North Miami Beach, FL. 12(8), 1-2.

49. Muir G. G. \& Blake S., (2000). Foundations of collaboration. Teaching Excellence: Towards the Best in the Academy. POD Network. North Miami Beach, FL. 11(7), 1-2. 
50. Nunamaker, J. F., Dennis, A. R., George, J. F., Valacich, J. S. \& Vogel, D. R. (1991). Electronic meeting systems to support group work: Theory and practice at Arizona. Communications of the ACM. 34(7), 40-61.

51. Nygrarg, J. (1991). Collaborative learning. Crosstalk: Humanities Division Adjunct Newsletter, Mercer County College, 1.

52. Orlikowski, W. J. (1992).The duality of technology: Rethinking the concepts of technology in organizations. Organization Science. 3(3), 398-427.

53. Palloff, R. \& Pratt, K. (2001). Lessons from the Cyberspace Classroom. Jossey-Bass San Francisco CA.

54. Poole, P. (2000). Teaching via interactive television: An examination of teaching effectiveness and student satisfaction. Journal of Education for Business. 72, 78-81.

55. Rice, R. E. (1984). Mediated group discussion. In Rice, R. (ed) The New Media. Sage. Beverly Hills CA, 129-154.

56. Rice, R. E. (1992). Task analyzability, use of new media, and effectiveness: A Multi-site exploration of media richness. Organization Science 3(4), 475-500.

57. Rice, R. E. \& Gattiker, U. E. (2001). New media and organizational structuring. in The New Handbook of Organization Communication (eds.) Jablin, F. M. and Putnam, L. L. Sage, Thousand Oaks. CA, 544-581.

58. Romeo, L. (2001). Asynchronous environment for teaching and learning: Literary trends and issues online. The Delta Kappa Bulletin. 6(3) 24-28.

59. Schmitz, J. and Fulk, J. (1991). Organizational colleagues, information richness, and electronic mail: A test of the social influence model of technology use. Communication Research. 18, 487-523.

60. Smith, K. \& Waller, A. (1997). Cooperative learning for new college teachers. In New Paradigms for College Teaching. (eds.) Campbell \& Smith. Interaction Book Co. Edina, MN.

61. Southard, S. (1993). Total quality management: From business to academe and back again to business. Paper presented at the annual meeting of Conference on College Composition and Communication. San Diego, CA, $1-12$.

62. Timmerman, C. E. (2004). Comparisons of video lecture formats in online communication classes. In Learning More About Learning: In the Trading Zone. (eds) Schroeder, C. M and Ciccone, A. Center for instruction and Professional Development, UW-Milwaukee, WI., 20-30.

63. Trevino, L. K., Daft, R. L., \& Lengel, R. H. (1990). Understanding managers' media choices: A symbolic interactionist perspective. In Fulk, J. and Steinfield, C. (eds.) Organizations and Communication Technology. Sage, Newbury Par, CA, 71-93.

64. Trevino, L. K., Webster, J. A., \& Stein, E. W. (2000). Making connections: Complementary influences on communication media choices, attitudes, and use. Organization Science. 11(2), 163-182.

65. Uchida, C. (1996). Preparing Students for the $21^{\text {st }}$ Century. American Association of School Administrators, Arlington VA.

66. Valacich, J., Paranka, D., George, J., \& Nunamaker, J. (1993). Communication concurrency and the new media. Communication Research. 20(2), 249-276.

67. Viverias-Dresler, G. \& Kutschke, M. (1992). RN students' satisfaction with clinical teaching in a distance education program. The Journal of Continuing Education in Nursing. 23, 224-230.

68. Wiener, H. S. (1986). Collaborative Learning in the Classroom: A Guide to Evaluation. College English. 48(1), 52-61.

69. Wolf, K. (1997) Predicting positive self-efficacy in group problem solving. Human Resource Development Quarterly, 8(2), 155-169.

70. Wright, V. H., March, G. E., \& Miller, M. T. (2000). A critical comparison of graduate student satisfaction in asynchronous and synchronous course instruction. Planning and Changing. 31, 107-118.

71. Yoo, M. \& Alavi, M. (2001). Media and group cohesion: Relative influences on social pretense, task participation, and group consensus. MIS Quarterly, 25(3), 371-391. 